\title{
EKOLOJİK ÜTOPYALAR
}

\section{Seçil Gül MEYDAN YILDIZ*}

\section{Özet:}

Mevcut sistemin aksayan yönlerini çözmeyi ve toplumun kaybolmaya yüz tutmuş değerlerini canlandırmayı amaçlayan, aynı zamanda bu süreci özgürlük, eşitlik ve barış düşüncesiyle birleştiren mükemmeliyet arayışı ütopyaları yaratmıştır. 20. yüzyılın ikinci yarısında kaleme alınan ekolojik ütopyalar, doğayla uyumlu, kırsal yaşam özünde idealleştirilmiş ve komün topluluklar biçiminde oluşturulmuş çağdaş kentleşme politikaları ortaya koymaktadır. Bu çalışmada ekolojik ütopyalardan, Ernest Callenbach'in, Ekotopya, Robert Havemann'ın Yarın: Yol Ayrımındaki Sanayi Toplumu Eleştiri ve Gerçek Ütopya ve Joel de Rosnay’in Le Macroscope ve Ortakyaşar İnsan yapıtları incelenmektedir. Ekolojik ütopyalar, ideal bir toplum düzeni ve sağlıklı bir kentleşme için tüketim alışkanlıklarının değiştirilmesi, doğaya saygılı olunması, insanın doğanın bir parçası olduğunun unutulmaması ve en önemlisi çevre bilincinin gelişmesi gerektiği konusunda önemli varsayımlar içermektedir. Bu çalışmada, üç ekolojik ütopyacının, sanayi devrimi, küreselleşme, makineleşme ve kalkınma gibi faktörlerin etkisiyle değişime uğrayan tüketim alışkanlıklarını doğa temelli değiştirmeye yönelik kurguladıkları kentsel yaşamlar karşılaştırılarak açıklanmakta ve bu sürecin güncel kentleşme süreçleriyle ilişkisi incelenmektedir.

Anahtar Kelimeler: Tüketim, Çevre, Ütopya, Ekotopya, Gerçek Ütopya, Ortakyaşam

\section{The Ecological Utopias}

\begin{abstract}
:
The search for perfection with the desire of solving the falling aspects of the system and reviving the almost-vanished values, at the same time combining this process with the idea

* Yrd. Doç. Dr. Bozok Üniversitesi, Şehir ve Bölge Planlama Bölümü, secilmeydan@ gmail.com
\end{abstract}


of freedom, equality and peace have resulted in utopias. The ecological utopias written in the second half of the $20^{\text {th }}$ century suggest contemporary urbanization policies idealized in the essence of rural way of living in the form of communal societies in harmony with nature. In this study, the ecological utopias including Ecotopia, work of Ernest Callenbach, Tomorrow, The Industrial Society at the Crossroads, Criticism and Real Utopia, work of Havemann and Le Macroscope and the Symbiotic Man, work of Joel de Rosnay are analyzed. Ecological utopias contain important assumptions about changing of consumption habits for an ideal social order and wealthy urbanization, being respectful to the nature, not forgetting that man is a part of the nature, and most important of all, the necessity for raising the awareness of environment. In this study, the urban lives fictionalized by the three ecological utopists directed at changing the habits of consumption changed under the influence of industrial revolution, globalization, mechanizing and improvement on the base of nature are compared and explained, and the relationship of this process with the contemporary urbanization processes is analyzed.

Keywords: Consumption, Environment, Utopia, Ecotopia, Real utopia, Symbiosis

\section{Giriş}

Sanayi toplumunun üretim-tüketim biçimi, örgütlenişi ve işleyişi kentsel ve çevresel sorunların temel kaynağıdır. Üretim ve tüketim süreçleri arasındaki etkinlikler ekoloji ve ekonomi arasındaki ilişkiyi çok yönlü kılmaktadır. Üretim sürecinden tüketim aşamasına kadar geçen süreçte ilk enerji girdisi, son enerji çıkışına denk olmadığında, dolayısıyla atıkların dönüştürülmemesi ya da değeri düşük bir kullanıma dönüştürülmesi ekolojik döngü içindeki dengesizlikleri artırmaktadır (Keleş, 2013: 101-102). Bu süreç geleceğin yaşam alanlarının ideal toplum düzeni içinde yeniden tasarlanmasını gerektirmektedir. Bu çalışmada sanayi toplumunun yaratmış olduğu tüketim kültürü ve tüketim kültürüne tepki olarak oluşturulan ekolojik ütopyalar incelenmektedir. Ekolojik ütopyalardan, Ernest Callenbach'in, Ekotopya, Robert Havemann'ın Yarın: Yol Ayrımındaki Sanayi Toplumu Eleştiri ve Gerçek Ütopya ve Joel de Rosnay'in Le Macroscope ve Ortakyaşar İnsan yapıtları ele alınmaktadır. Bu makalede metot olarak literatür incelemesine yer verilmiştir. 


\section{I. Çevre-Ekoloji Kavramları ve Tüketim Toplumu}

Çevre sözcügünün bakış açısına göre değişebilen dar ve geniş anlamları bulunmaktadır (Keleş, 2013: 23). Türk Dil Kurumu'nun Türkçe Sözlügünde (2016), çevre kavramı dar anlamıyla a) bir şeyin yakını, dolayı, etraf, periferi b) kişinin içinde bulunduğu toplumu oluşturan ortam c) aynı konu ile ilgisi bulunan kimselerin tümü, muhit d) bir kimse ile ilişkisi bulunanlar, muhit e) bir birimden önce veya sonra gelen aynı türden birimlerin tümü, bunların oluşturduğu küçük grup f) düzlem üzerindeki bir şekli sınırlayan çizgi g) hayatın gelişmesinde etkili olan doğal, toplumsal, kültürel dış faktörlerin bütünlügü olarak açıklanmaktadır.

Çevre, Kentbilim Terimleri Sözlüğünde: “Kişiyi etkileyen, özdeksel ve tinsel (maddi ve manevi olmayan) gelişmesini, biçimlenmesini ve yaşamını belirleyen, dirimbilimsel (biyolojik), iklimle ilgili ve toplumsal etkenlerin tümü” (Keleş, 1998) şeklinde geniş ve kapsamlı tanımıyla verilmiştir. Çevreye ilişkin konuların çeşitliliği, derinliği, çok boyutlu bir yaklaşım gerektirmesi ve çevre ile ilgili değerlerin, sorunların ya da politika ve yaklaşımların bütüncül bir şekilde ele alınması zorunluluğu, kavramın tanımını da kendisi kadar karmaşık hale getirmektedir.

Ekoloji, biyolojinin bir kolu olarak ortaya çıkmış ve gelişmiştir. Kökenbilimsel (etimolojik) olarak yerleşme bilimi ya da yurt anlamlarını içermektedir. Uzun yıllar ilgi çekmeyen ve bilim dünyasında genellikle geri planda kalan ekoloji, 20. yüzyılın sonlarına doğru hızlı nüfus artışı, besin kıtlığı, çevre kirliliği gibi sorunların etkisiyle en önemli bilim dallarından biri olarak öne çıkmıştır (Keleş vd., 2009: 46). Ekoloji önceleri hayvan ve bitki ekonomisi olarak kullanılırken günümüzde tüm canlı ve cansız varlıkları ve onların birbirleriyle olan etkileşimlerini kapsayan geniş bir anlam kazanmıştır. Ekoloji, canlı organizmaları ve bu organizmaların çevreleri ile olan ilişkilerini konu alan bir disiplindir. Modern ekolojinin kurucusu olarak görülen Eugene Odum’un 'Ekolojinin Temel İlkeleri (1971)' adlı kitabına göre ekoloji, ekosistemlerin işlevlerini inceleyen bilim dalıdır. Bir başka deyişle, ekoloji, ekosistemlerin niceliksel ve matematiksel olarak çalışabilmeleri 
için temeli oluşturan enerji akımı, kimyasal madde döngüsü ve popülasyon denetimi işlevlerini incelemektedir.

Tüketim alışkanlıkları, yaşanılan toplumun tarihsel süreç içerisinde belirlemiş olduğu kültürel unsurlarının bir birikimidir. Tüketim kültürü, kapitalist gelişme ve refah toplumunun yükselişiyle paralellik gösterir (Aytaç, 2006: 30). Modern kapitalizm bir tüketim döngüsü içinde yer almaktadır. Üretim ve tüketim süreçleri arasındaki etkinlikler ekoloji ve ekonomi arasındaki ilişkiyi çok yönlü kılmaktadır. Aşırı tüketim küresel ölçekte sorunlar yaratan kentsel ve çevresel bir suçtur.

Doğal nüfus artışı ve göçün etkisiyle demografik yapıda oluşan değişimler; moda, reklam, pazarlama, saygınlık, bireysel düşünce ve davranış gibi konularda da değişime yol açmakta, ayrıca teknolojiye bağlı yenilikler ve yaşam standartları, tüketici davranışlarını sürekli değiştirmektedir. Dolayısıyla yeni yaşamsal ve çevresel gereksinmeler yeni konut, çalışma, dinlenme ve eğlenme gibi bir dizi farklı alan kullanımlarına ve sonuç olarak yeni kentsel maliyetlere ve kentsel toprakta değer artışına yol açmaktadır.

Kelime anlamı olarak, tüketme kavramı, tahrip etmek, harcamak, israf etmek, bitirmek anlamlarını içermektedir (Aytaç, 2006: 30). Tüketim, emeğin, kaynakların ve iş gücünün sömürüsüne dayanmaktadır. Eşitsizlik, sevgisizlik, güvensizlik gibi olgular tüketim kültürünün oluşturduğu bencillik olgusunun ve bu olguyu geliştiren kapitalizmin yaratmış olduğu aşırı tüketme duygusudur (Odabaşı, 2013: 181). Kapitalizmle tüketim, ideoloji, üstünlük miti, hiyerarşik kıstas ve sınıfsal temsil aracı haline dönüşmüştür (Aytaç, 2006: 28).

Kapitalist sistem içinde, sermaye, yaşam koşullarını yönlendiren bir pusula gibidir. Sanayi kenti, bireyin arzu ettiği her şeye ulaşmayı hedefleyen bir tüketiciye dönüşmesine, kullan ve at bakış açısına ve bireyin ben-merkezci düşünceyi doğal bir davranış olarak görmesine neden olmuştur. Değer yargıları, manevi kültürel unsurlar içinde yer alan, uzun zaman diliminde oluşan ve değişimi zor bir kültürel birikimdir. Sistemin unsurlarıyla birleşen tüketim kültürü kentsel ve çevresel de- 
ğerlere olan bakış açısını değiştirmektedir. Kapitalist bakış açısında, bir malın kullanım değeri değil; kazanma ve servet biriktirme boyutu önemlidir.

Teknoloji ve iletişim araçlarında yaşanan gelişme üretim düzeyleri farklı olan toplumları etkilemekte ve ileri teknolojiye sahip, sanayileşme sürecini tamamlayarak bilişim teknolojisi bilincine ve değerler sistemine ulaşan ülkeler, gelişmekte olan ülkeleri etkilemektedir. Kentleşme süreci sanayileşme ile uyumlu gelişmeyen ülkemizde, tüketim toplumunun değerler sistemi ve geleneksel değerler arasında kalmaktadır.

Tüketim ve tüketici ilişkisi Douglas ve Isherwood'a göre:

"Tüketicinin en genel amacı sadece, seçtiği mallarla kavranılabilir bir evren inşa etmek olabilir. Bu öğrenme süreci nasıl gerçekleşir? Başlangıç olarak, toplumsal bir evren, bir zaman boyutunun işaretlenmesini gerektirir. ...bu tüketimde mekan kavramı için de geçerlidir; kültürel sürecin hizmetine koşulan mekanın bölümleri anlamla yüklüdür: konut, boyutlar, sokak cephesi, öbür merkezlerden uzaklik, özel sinırlar; bunlartn hepsi kavramsal kategorilere dayanak olurlar" şeklinde tanımlanmaktadır (Aktaran: Tandaçgüneş, 2011: 105).

Bireysel değerler ve gereksinimlerden çok, toplumsal standartlaşmalar ve bir zaman boyutu içinde oluşan maddi ve manevi olarak benimsenen kültürel süreçler tüketimi etkilemektedir. Dolayısıyla bireylerin dünyaya bakış açıları, dünyay1 anlama ve anlamlandırma biçimleri değiştiğinde, tüketim alışkanlıkları değişmektedir. Tüketim kültürü ve tüketici ilişkisinde, kent yaşamı ve değişen tüketim alışkanlıkları birey ve toplum ilişkisini de değiştirmektedir.

Tüketim kavramına yönelik Warde'ın:

“insanların kendi kimliklerini göstermesi, sosyal gruplara katılmayl gösterme, kaynakları biriktirme, sosyal farklllkları gösterme, sosyal etkinliklere katılma ve bunlar gibi pek çok şeyi sağlayan bir dizi uygulamayı kapsar" (Aktaran: Thorns, 2004: 121) şeklindeki tanımı tüketimin toplumsal ayrışmanın bir ifadesi olan yaşam tarzının, statünün, saygınlığın ve kimliğin yansıması olduğunu göstermektedir. 
Tüketilen şey, sosyal gruplar ve bireyler arasındaki farkl1lığı yansıtmakta, tüketicilerin ürünlere yükledikleri anlamlar statülerini ve grup aidiyetlerini göstermektedir. $\mathrm{Bu}$ durum, temel yaşamsal gereksinimlerin tatmininden çok, rahatlık, konfor, gösteriş ve rahat yaşamayı bir hak olarak gören bakış açısının bir sonucudur (Odabaş1, 2013: 175).

Tüketim kültürü, egemen ideolojik yapılar ve kurumlar tarafından sürekli desteklenmekte, teşvikler ve baskılarla ilgi uyandırılarak, bireylerin mevcut tüketim kalıplarına uyması sağlanmaktadır. Oysa, kapitalist toplumun, sürekli tüketimi artırma ve üründen en yüksek verimi sağlama mantığı birbiriyle çelişmektedir. A. Gorz’a göre:

"Toplumun ekolojik olarak yeniden yapılanmast, ekonomik rasyonalitenin, ekososyal bir rasyonaliteye tabi kılınmasın gerektirir. Bu bağımlılık, verimliliğin ve kârın en düşük seviyeye getirilmesine yönelik kapitalist paradigmayla uyum içinde değildir. Bu rekabet halindeki işletmeleri yenilenmeye ve sunuların sürekli olarak farklılaştırmaya, yeni istekler yaratmaya, mümkün olduğunca büyük bir tüketimle tatmin bulmaya ve kendine yeterli üretime ve seçilmiş zamana yöneltilecek olan ihtiyaçların öz sinırlanışını engellemeye zorlayan bir pazar ekonomisi ile uyum içinde değildir" (Aktaran: Kılıç, 2013: 99).

Günümüzde, bireylerin daha iyi, pahalı, çeşitli ve haz yaratan, sembolik değerlere sahip ürünleri edinmeleri ve tüketmeleri, başarıların ve belli bir sosyal sınıfa ait olmanın göstergesi ve sembolü haline gelmiştir. Yüksek gelir gruplarının yeşille iç içe, doğa manzaralı, kentsel gürültü gibi diğer kirliliklerden uzak alanlarda imar uygulamalarını başlatmaları, arsa vurgunculuğu ve baskı ve çıkar gruplarının planlama kararları üzerindeki etkileri mekansal tüketimin nedenlerinden olup, bu durum, uzun vadede, orman alanlarının, göllerin, kıyıların ve doğal değere sahip alanların rant yaratılarak tüketimine yol açmaktadır.

Geleneksel toplumdan, çağdaş topluma geçen ülkemizde, geleneksel değerler terk edilerek güvenli, huzurlu ve mutlu bir yaşamın tüketimden geçtiği yönündeki politikalarla tüketim özendirilerek çalışma, mal edinme, ilerleme, gelişme gibi de- 
ğerler beraberinde, iletişimsizlik, yalnızlık, huzursuzluk, bağ kuramamak gibi durumları ortaya çıkarmaktadır. En iyi olma arzusunun yarattığı yarış ve rekabet ortamı ülkeleri, kentleri ve bireyleri esir almaktadır (Odabaşı, 2013: 183). Bireyin kendi geleceğini bile düşünmeden kapıldığı tüketme hırsı insanı doğaya yabancılaştırmaktadır.

\section{Ekolojik Ütopyalar}

20. yüzyılın ikinci yarısında kaleme alınan ekolojik ütopyalar, doğayla uyumlu, kırsal yaşam özünde idealleştirilmiş ve komün topluluklar biçiminde oluşturulmuş çağdaş ütopyalardır (Tandaçgüneş, 2011: 104). Çağdaş ekolojik ütopyalar, Ernest Callenbach, Ekotopya, Robert Havemann Yarın: Yol Ayrımındaki Sanayi Toplumu Eleştiri ve Gerçek Ütopya ve Joel de Rosnay'in Le Macroscope ve Ortakyaşar İnsan, iyi toplum düzeni için tüketim alışkanlıklarının değiştirilmesi; yaşamın sürekliliği için doğaya saygılı olunması, insanın doğanın bir parçası olduğunun unutulmaması ve en önemlisi çevre bilincinin gelişmesi gerektiği konusunda önemli varsayımlar içermektedirler (Keleş, 2014).

Ernest Callenbach, Ekotopya (1975) isimli çevreci ütopyasıyla doğal kaynakların öncellikle güneş ve su enerjisinin en yüksek verimlilikte kullanıldığı, üretimde ve tüketimde akılcılığın savunulduğu bunun yanı sıra arabaların olmadığı, erişilebilirliğin yaya temelli geliştiği, cinsiyet ayrımcılığının olmadığı, kadın, çocuk ve emekçi haklarının savunulduğu eşitlikçi bir toplum tasarlamaktadır (Callenbach, 2010, Keleş, 2013: 185). Kültürel, ekonomik ve siyasal açıdan önemli çözümlemeler içeren kentsel yaşam, dengeli ve düzenli nüfus yapısına sahiptir. Bisiklet şeritleri, çeşmeler, heykeller ve aktif yeşil alan kullanımına ayrılmış olan mekan, serbest zaman etkinlikleriyle doludur. Aceleciliği, tüketimi, sürümü ve sermayeyi benimseten kapitalist ekonominin kültürel unsurları, duyarlı1ık, doğaya uyum ve sakinlik içinde çevre bilinciyle değişmektedir. Biyolojik ve ekonomik süreçler arasında denge sağlamaya çalışılmakta ve teknolojinin yıkıcı etkisi en aza indirilmektedir. Teknoloji doğayla uyum sınırı içinde özellikle geri dönüşüm, çöp ve atık uygulamalar kapsamında detaylı olarak ve özveriyle kullanılmaktadır. Toplu taşı- 
ma sistemlerine yönelik teşvikler bulunmaktadır. Ekotopya'da reklam afişleri ve tabelalar yapaylık ve görsel kirlilik olarak ele alınır. Sokak işaretleri çok az sayıda olup küçük oranda ve görsel kirlilik yaratmayacak şekilde yapılara yerleştirilmiştir. Kentsel birçok sorun, toplumsal maliyet unsurları ve ahlaki ikna mekanizması içinde çözümlenmektedir. Psikolojik olarak güçlü, duyarlı, birbirleriyle iyi geçinen ve yardımsever olan Ekotopyalı için, mülk, statü ve güç değersizdir. İnsanların saygınlık kazanmaları, pratikteki başarılarına bağlı olup, hem kişisel vasıflar, hem de topluma yararlı olacak yaratıcılık ve mucitlik ödüllendirilmektedir. Eğitim, becerilerin artırılabileceği ve pratik kazanılabilecek alanlara yönelmiştir. Yirmi saatlik çalışma haftası serbest zaman aktiviteleri için olanak sağlamaktadır. Böylece yaşamaktan zevk alabilen, kurulu bir makine olarak çalışmak zorunda olmayan bireyler, toplumsal yarara dayalı bir cömertlikle daha verimli çalışmaktadır. Toprak, Kızılderili inancı esas alınarak kutsallaştırılmıştır. Geleceğe umutla bakılmakta ve teknolojinin ve bilimin insanlığın hizmetinde doğa yasalarına uygun bir şekilde gelişeceğine inanılmaktadır (Callenbach, 2010).

Robert Havemann, Yarın: Yol Ayrımındaki Sanayi Toplumu Eleştiri ve Gerçek Ütopya (1979) yapıtında, kapitalist sistemin temel çelişkilerini ele alarak çevresel, kentsel ve toplumsal sorunların kapitalizmle çözülemeyeceğini savunmaktadır (Havemann, 2005, Keleş, 2013: 185). Robert Havemann’ın, tüketim alışkanlıklarının değiştirilmesiyle sürdürülebilir bir kalkınmanın ve ideal bir toplum düzeninin sağlanacağını vurguladığı ütopyasında, devlet, polis ve asker gibi güvenlik güçleri bulunmamaktadır. İdari yapının olmadığı toplumsal düzende başkente ve başkentin karmaşık mekansal yapılanmasına ihtiyaç yoktur. Kent, bilim, sanat, teknoloji ve eğitim-öğretim ünitelerinden oluşmaktadır. Doğa ile iç içe kurgulanan yaşam alanları doğanın sunduğu olanaklar çerçevesinde dağınık olarak yer seçer ve yaya ulaşımına uygundur. Çalışma alanları, eğitim ve yaşam alanlarıyla iç içedir. Herkes ütopya yararına çalışmakta, yapacağı işi ilgi alanına göre kendisi seçmekte ve seçtiği işe devam edip etmeme konusunda özgür olmaktadır. Herkesin çalıştığı toplumda, genç veya yaşlı bağımlı nüfus kavramı bulunmamakta ve dengeli bir 
nüfus kurgulanmaktadır. Sevgi üzerine kurgulanan toplumsal düzende, hırs, kıskançlık, sömürü, en iyisini elde etme ve sahip olma arzusu, unvan ve mülkiyet yoktur. Böylece tabular ve ahlak kuralları da ortadan kalkmıştır. Üretim ve bölüşüm elektronik bilgi işlem merkezleri tarafından yapılmakta olup yaşamak için gerekli tüm üretim sistemleri otomatikleşmiştir. Modern tarım teknikleri kullanılmakta ve seracılığa önem verilmektedir. Ağır sanayi üretiminin gerekli olmadıkça yapılmadığı Ütopya'da demiryolu, havayolu ve otoban gibi hava ve gürültü kirliliğine yol açan kullanımlar yoktur. Tüketmeme kültürü benimsenerek tüm yaşamsal gereksinimlerde eskimeyen ve uzun ömürlü maddelerin kullanımı sağlanmaktadır. Kapitalist ekonominin yücelttiği rekabet, kâr ve moda önemini yitirmiştir.

Ütopya'da, ütopik yaşam kültürel devrimle birkaç kuşak sonra kendiliğinden oluşur. Eski düzende, normal kabul edilen kentsel yapılanmalar gökdelenler, betonlar ve devasa yollar gelecek nesillerin ibret alması için kendi kaderine bırakılarak barbarlı̆̆ın ve çözümsüzlüğün eseri olarak korunmaktadır. Ütopya'da liman ticareti önemlidir. Enerji üretiminde ileri teknoloji kullanılmaktadır. Radyoaktif atıklara yol açan nükleer santrallerin kullanımı yasaktır. Ekolojik sorunlara yol açmayan hidrojen füzyonu reaktörler ve yenilenebilir enerji kaynakları en yüksek verimlilikte kullanılmaktadır. Sahip olmamanın zenginlik olarak sayıldığ 1 Ütopya’da insan ilişkileri uyum içinde olup cinsel ayrımcılık, evlilik ve kapalı aile ilişkileri yoktur. Çocuk köylerinde yapılan ve toplu yaşamı gerekli kılan sosyokültürel faaliyetler herkesi aktif ve yaratıcı biçimde ütopik kültürün bir parçası yapar.

Joel de Rosnay’in Le Macroscope (1975) ve Ortakyaşar Insan Üçüncü Binyıla Bakışlar (1995) yapıtlarında, geleceğin insanını ortakyaşar insan olarak kurgulamıştır (Rosnay, 2014, Rosnay, 1998). Mikro-organizma olarak tanımlanan siber-canlı, insanlar ve insanların yaratmış olduğu teknik, teknoloji, mekanik ve kültürel ağlardan oluşan canlı bir sistemi temsil etmektedir. Makro-organizmanın yaşamsal dokuları canlı bir organizmanınki gibi farklılaşarak çeşitlenmektedir (Rosnay, 2014). Bilgisayarlarla bağlanan gezegen çapındaki iletişim ağları, siber- 
canlının sinir sisteminin ve beyninin ilk aşamalarıdır. İnsan tarafından yaratılan neobiyoloji gelişerek yeni bilimleri yaratmakta, bu bilimsel ve teknolojik gelişim, insanın çevresinde önce mekanik, sonra da toplumla ilişkisi sayesinde biyoelektronik yeni bir doku yaratarak makro-organizmaya bağlanmaktadır. Toplumsal yaşam mekanik, sanal ve yapay gelişimlerle şekillenerek yeni bir ekosistem dengesi kurmaya başlamaktadır. Dolayısıyla, Rosnay'in ütopyası, yapay doğa ile doğal yapaylık arasında bir farkın kalmadığı, doğal-yapay, gerçek-sanal, maddesel ve maddesel olmayan arasındaki sınırların silindiği bir yaşam ortamına dönüşmektedir. Olağanüstü çeşitlilikte olan ve insanoğlunun kendi yararına yaratmış olduğu yapay çevre, zamanla denetlenemeyen özerk evrimlerle karşı karşıya kalacaktır. Böylece, daha geniş bir çerçevede insanlığı da kapsayan bir üst karmaşık düzeyde yeni bir organizma ortaya çıkmaktadır. İnsan ile yeni organizma arasındaki ilişki ortakyaşar insanı doğurmaktadır (Rosnay, 1998).

Rosnay'e göre, tarım ve enerji metabolizması sayesinde kendini kurma ya da sürdürme, sanayi ve ekonomi ile kendini üretme ve bilgisayar ve bilgi ağlarıyla kendini düzenleme yeteneğine sahip olan siber-canl1, enerji, enformasyon, ekonomi ve ekoloji bileşenlerinden oluşmaktadır. Öyle ki siber-canlı, makro-biyolojinin rasyonel olarak tasarlanıp denetlenmesinden meydana gelir. Makro-biyoloji disiplini, insanla makro-organizma arasındaki ortakyaşam ilişkisi üzerine kurulmaktadır. Bu ilişki de insan beyni ile gezegenin beyni arasında yeni arabirimleri gerekli kılmaktadır. Ortakyaşam, insanın, gezegenin beynini oluşturan bilişim ağlarıyla olan ilişkisini yansıtır. Rosnay, insan beyniyle bilgisayar beyni arasındaki dolaysız ilişkiyi ele almaktadır. Ütopyasının gerçekleşebilir olduğunu güncel biyolojik ve teknik gelişmelerle destekleyen Rosnay, bilgisayarlar ve ağlar arasındaki ortakyaşam sürecinin insanlığın vazgeçilmez bir parçası olduğunu sınai, mali, idari, ticari, askeri vb. büyük telepatik sistemlerin gezegeni etkilediğini ve gün geçtikçe insanlığın siber dünyaya bağımlılığının artacağını belirtmektedir. Özellikle son yıllarda bilgisayarların insan duyu organlarıyla benzer organlarla donatılmaya başladığını ve bilgisayarın insanı öğrenmesiyle, insanla bilgisayar arasındaki ortakyaşamın 
daha ayrıntılı ve derin bir işlev kazandığını belirten Rosnay, insanı, toplumu, teknolojiyi ve gezegeni, birlikte-evrim içinde, bir bütün olarak ele almaktadır. Rosnay için, bin yıl sonraki insan betimlemesi birçok bilim adamının ve bilim kurgu yazarının tanımladığı gibi ne RoboCop, Terminatör, yarı-insan yarı-robot gibi bir sibernetik canlı, ne teknolojiyi üst düzey kullanan kısa boylu, kafası büyük ve sökülüp takılabilen duyu ve organlara sahip, ne de işınlanma sayesinde yürüme yeteneğini unutan minicik bacaklı, yoğunlaştırılmış (konsantre) besinlerle beslendiğinden dişi olmayan bir fiziksel yapıdadır. Rosnay’e göre, geleceğin insanı, beden ve zihin bakımından 20. yüzyıl insanından farklı değildir. Ama siber-canlıyla kurduğu biyolojik, psikolojik veya biyonik bağlantılar sayesinde, insanoğlu, olağanüstü bilgi ve eylem olanaklarına sahiptir. Bu siber-canlı, yani makro-organizma, ilkel bir halde olmasına rağmen birçok yönüyle şimdiden, kentleri ve kırsal yaşam alanlarını, ulaşım ağlarını ve iletişimi kendi dinamiği içinde sürdüren yaşamsal organ ve dokulara sahip bir yapıda hızla üreyerek çoğalmakta ve çeşitlenmektedir.

Siber-canlının ilişki ağları, toplumu, ekonomik ve ekolojik yapıları kendine özgü kurallarıyla yeniden kurgulamaktadır. Rosnay’e göre, üçüncü bin yılda kentler, doğrudan gözle görülebilen makro-dünya alanları olarak varlığını sürdürecektir. Ancak yeni iletişim, ulaştırma ve büyük insan yapılarına sonsuz çeşitlilikte yapay manzaralar eklemektedir. Görünmeyen makro-dünya alanları ise ekonomi ve ona bağlı sayısız işlem ağından oluşacaktır. Çiftlik yaşamı insanla doğa arasında ileri düzeyde bir ortakyaşamı temsil etmektedir. Rosney'in ütopyasında, kırsal kesimler biokütlenin enerji mekanizmaları olarak kurgulanmaktadır. Üçüncü binyılın kentlileri, ego-yurttaş bakış açısından uzaklaşarak, eko-yurttaş bilincine sahip olacaktır. Rosnay bu süreci, 'her birimiz kendine' ilkesinin bırakılıp 'her birimiz herkese' görüşüne yönelme olarak tanımlamaktadır. Dolayısıyla, gerçek bir ortakyaşamın mümkün olabilmesi, bireylerin tutum değiştirerek doğa ile yapay çevre (ağlar sistemi) arasında bütüncül bir bilinç oluşturmasıyla gerçekleşebilir. Rosnay'in geleceğe yönelik tasarısında çevre ve mekanik-teknolojik sistem uyum içindedir ve birlikte evrimleşmektedir. Ekonomi ve ekoloji arasında kurulacak olan 
ortakyaşam ilişkisi makro-organizmanın ve insanlığın varlığını sürdürebilmesi için zorunludur. Rosnay için bu süreç, insan-merkezci bakış açısından çıkıp, çevremerkezci yaklaşımlara yönelmeyi gerekli kılmaktadır. Toplumcu bakış açısı, insanların özel arabalarını başkalarıyla paylaşabilmesi gibi birçok açıdan enerji tasarrufu ve geri-beslenimi özendirecek yönetişim anlayışlarını içermektedir. Rosnay'in üçüncü binyıl için önerileri; a) demografik geçişi sürdürerek hızlı nüfus artışını dengelemek, çocuk sayısını düşürmek ve kadının toplumdaki statüsünü artırmak, b) askeri harcamaları azaltarak sağlık, eğitim, çevre ve enerji alanlarına yönelik yatırımları artırmak, c) siber-canlının metabolizmasını çalıştıracak ve doğa ile ortakyaşam sağlayacak dengeli bir enerji politikası oluşturmak, ç) kendi kendini düzenleyen bir ortakyaşam ekonomisi ortaya koymak, d) çevresel etkileri, yerküre çapında eko-etik anlayışıyla denetlemek, e) herkese temel sağlik, eğitim hizmeti sunmak ve kültürel değerleri korumak, f) gerçek ve sanal ulaşım ağlarını geliştirmek, g) toplumun gereksinimlerine odaklanmış uyumlu teknolojiler geliştirmek, ğ) toplu taş1mayı biçimlendiren, mahalle-sokak yaşamını canlandıran, kirletici teknik altyapıyı çevre odaklı dönüştüren yeni kent projeleri geliştirmek, h) yönetişim ve toplumsal geri-beslenim mekanizmalarıyla uyumlu katılımcı, adaletli ve eşitlikçi ilkelerle beslenen eko-yurttaş, biyo-etik ve çevre-merkezci bakış açısına sahip ortakyaşam kurgulamaktır (Rosnay, 1998).

\section{Sonuç}

Ekolojik ütopyalar, ideal bir toplum düzeni ve sağlıklı bir kentleşme için tüketim alışkanlıklarının değiştirilmesi, doğaya saygılı olunması, insanın doğanın bir parçası olduğunun unutulmaması ve en önemlisi çevre bilincinin gelişmesi gerektiği konusunda önemli varsayımlar içermektedir (Keleş, 2014: 59-62). Ernest Callenbach, Ekotopya (1975) isimli ekolojik ütopyasıyla doğal kaynakların öncellikle güneş ve su enerjisinin en yüksek verimlilikte kullanıldığı, üretimde ve tüketimde akılcılığın savunulduğu, bunun yanı sıra arabaların olmadığı, erişilebilirliğin yaya temelli geliştiği, cinsiyet ayrımcılığının olmadığı, kadın, çocuk ve emekçi 
haklarının savunulduğu eşitlikçi bir kent tasarlamaktadır. Robert Havemann, Yarın: Yol Ayrımındaki Sanayi Toplumu Eleştiri ve Gerçek Ütopya (1979) yapıtında, kapitalist sistemin temel çelişkilerini ele alarak çevresel, kentsel ve toplumsal sorunların kapitalizmle çözülemeyeceğini savunmaktadır. Tüketim alışkanlıklarının değiştirilmesiyle sürdürülebilir bir kalkınmanın ve ideal bir toplum düzeninin sağlanacağının vurgulandığı Gerçek Ütopya'da devlet, polis ve asker gibi güvenlik güçleri bulunmamaktadır. Kentsel yaşam, bilim, sanat, teknoloji ve eğitim-öğretim ünitelerinden oluşmaktadır. Joel de Rosnay'in Le Macroscope (1975) ve Ortakyaşar İnsan Üçüncü Binyıla Bakışlar (1995) yapıtlarında, geleceğin insanını ortakyaşar insan olarak kurgulamıştır. Mikro-organizma olarak tanımlanan siber-canlı, insanlar ve insanların yaratmış olduğu teknik, teknoloji, mekanik ve kültürel ağlardan oluşan canlı bir sistemi temsil etmektedir. Kentsel çevrenin mekanik, sanal ve yapay gelişimlerle şekillenerek yeni bir ekosistem dengesi kurmaya başlayacağını belirten Rosnay'in ütopyası, yapay doğa ile doğal yapaylık arasında bir farkın kalmadığı, gerçek-sanal, maddesel ve maddesel olmayan arasındaki sınırların silindiği bir kenti tanımlamaktadır.

Üç ekolojik ütopyacının da, sanayi devrimi, küreselleşme, makineleşme ve kalkınma gibi faktörlerin etkisiyle değişime uğrayan tüketim alışkanlıklarının, doğa temelli değişmesi üzerine yeni bir toplumsal yapılanma kurguladığını, doğaya ve kendine yabancılaşan insanoğlunun daha sağlıklı, daha düzenli, daha adil ve daha eşit bir dünya düzeni için doğayla bütünleşmesi ve ekonomi-ekoloji dengesini sağlaması gerektiğini önerdiklerini görmekteyiz. Bu öneriler eko-kent modelinin kavramsal temelini oluşturması açısından önemlidir. Ayrıca üç ütopyacı da, dengeli bir nüfus yapısı, yaya öncelikli ulaşım ağları, aktif yeşil alanlarla çevrili sağlıklı kentler ve hoşgörü üzerine kurulmuş bir toplumsal yapı tasarlamaktadır. Bunun yanı sıra, Rosnay tarafından ortaya koyulan siber-canlı ve enformasyon bileşenlerinin, günümüzün hızla artan bilimsel ve teknolojik gelişmeleri ve küreselleşme politikaları doğrultusunda ele alındığında diğer ütopyacılardan farklılaşarak öne çıktığı görülmektedir. 


\section{Kaynakça}

Aytaç, Ömer. (2006). “Tüketimcilik ve Metalaşma Kıskacında Boş Zaman”, Kocaeli Üniversitesi Sosyal Bilimler Enstitüsü Dergisi, 11 (1), 27-53.14

Callenbach, Ernest. (2010). Ekotopya, Çev.: Osman Akınhay, Agorakitaplığı, 2. Baskı, İstanbul: İdil Matbaac1lı.

Havemann, Robert. (2005). Yarın: Yol Ayrımındaki Sanayi Toplumu Eleştiri ve Gerçek Ütopya, Çev.: Filiz Özçelik, 1. Baskı, İstanbul: Kaynak Yayınları.

Keleş, Ruşen. (2015). Kentleşme Politikasl, 14. Baskı, (Mart), Ankara: İmge Kitabevi.

-------. (2014). 100 Soruda Türkiye'de Kentleşme, Konut ve Gecekondu, 1. Baskı, (Şubat), İstanbul: Cem Yayınevi.

-------. (2013). 100 Soruda Çevre: Çevre Sorunları ve Çevre Politikası, İzmir: Yakın Kitabevi.

-------. (1998). Kentbilim Terimleri Sözlüğ̈̈, Ankara: İmge Kitabevi.

--------. (1987). "Kentleşme ve Çevre Politikaları", Şehirleşme ve Çevre Konferansı, Türkiye Çevre Sorunları Vakfı Yayınları.

Keleş, Ruşen, Hamamcı, Can, Çoban, Aykut. (2009). Çevre Politikası, Ankara: İmge Kitabevi.

Kılıç, Selim. (2013). Çevre Etiği, Ankara: Orion Kitabevi.

Meydan Yıldız, Seçil Gül. (2016). "Çevre Bilinci ve Eko-Kent Planlaması: Gölbaşı Özel Çevre Koruma Bölgesi Örneği”, Yayınlanmamış Doktora Tezi, Ankara Üniversitesi Sosyal Bilimler Enstitüsü, Ankara.

Odabaşı, Yavuz. (2013). "Tüketim Toplumu”, Ekonomi Sosyolojisi, Editörler: Veysel Bozkurt, Fatime Güneş, Yayın No: 2303, 172-191, Eskişehir: Anadolu Üniversitesi Yayınları.

Rosnay, Joel de. (1998). Ortakyaşar İnsan Üçüncü Binyıla Bakışlar, Çev.: İsmet Birkan, 1. Baskı, İstanbul: Telos Yayıncılık.

Rosnay, Joel de. The Macroscope, http://pespmc1.vub.ac.be/macrbook.html, (Erişim Tarihi: 07.11.2014).

Tandaçgüneş, Nilnur. (2011). "Pazarlama İletişiminde Sürdürülebilir Tüketim Olgusuna Farklı Bir Bakış: Ernest Callenbach ve Ekotopya Yapıtı Üzerine Hermeneutik Okuma Çalışması”, İstanbul Üniversitesi İletişim Fakültesi Dergisi, Sayı: 41, s. 103-124. 
Thorns, David C. (2004). Kentlerin Dönüşümü Kent Teorisi ve Kentsel Yaşam, Çev.: Şahin Bingöl, Gözde Çetin, İstanbul: Soyak Yayınları.

Türk Dil Kurumu. (2016). Türkçe Sözlük, http://tdk.gov.tr/index.php?option=com_bts\&ara ma =kelime\&guid= TDK.GTS.58887bb58a95a7.62560979, (Erişim Tarihi: 29.12. 2016). 